\title{
ESTUDO SOBRE O NÍVEL DE ENTENDIMENTO DOS PROFISSIONAIS CONTÁBEIS DA CIDADE DE ICÓ/CE COM RELAÇÃO À RESPONSABILIDADE SOCIAL CORPORATIVA
}

\author{
Tayssa Vieira Barreto ${ }^{1}$ \\ João José Anselmo dos Santos²
}

\begin{abstract}
RESUMO
O presente artigo $^{3}$ almejou analisar o nível de entendimento dos profissionais contábeis com relação à Responsabilidade Social Corporativa (RSC), além de apresentar a Ciência Contábil em sua vertente social. Para isso foi realizada uma pesquisa de campo de natureza exploratória, com abordagem quantitativa, junto aos profissionais de escritórios contábeis da cidade de Icó/CE no período entre julho e outubro de 2014. O instrumento utilizado para a realização da pesquisa foi um questionário contendo 14 questões objetivas. Dentre os temas abordados foi realizado um embasamento teórico do contexto histórico da RSC, sua abordagem conceitual e as normas para a execução da mesma com enfoque nos princípios International Organization for Standardization (ISO) 26000 , além do aspecto contábil. Averiguou-se que a maior parte dos investigados considera que a contabilidade vai além do campo econômico-financeiro e afirmaram convictos que exaltam a importância de apresentar demonstrativos que expressem a RSC das organizações. A ênfase também foi atribuída à contabilidade como ferramenta de mensuração e execução da responsabilidade socioambiental destacando o Balanço Social (BS) e a Demonstração do Valor Adicionado (DVA). Observou-se que a busca por atualizações ocorre de maneira gradativa, uma vez que durante o processo de formação dos profissionais não havia conhecimentos sobre RSC e os que haviam se davam de maneira superficial. Portanto, constatou-se que os profissionais consideram a contabilidade dinâmica e o contabilista profissional capacitado a exercer sua função social, não somente como um cidadão preocupado, mas como um profissional eficaz na promoção do bem-estar social.
\end{abstract}

Palavra-chave: Responsabilidade Social Corporativa. Balanço Social. DVA. Contabilidade.

Recebido em: 20/03/2016 | Aceito em: 29/07/2016

\footnotetext{
${ }^{1}$ Bacharel e Ciências Contábeis pela Faculdade Vale do Salgado - FVS. Professora do Curso de Ciências Contábeis da FVS. Especialista Gestão Financeira, Auditoria e Controladoria pela FVS. Especialista em Docência do Ensino Superior pela FVS. E-mail: as.syta@hotmail.com

2 Formado em Agronomia pela UFC e mestrado em Irrigação e Drenagem pela UFC. Especializando em Marketing e Recursos Humano pela FVS. Professor titular da Faculdade Vale do Salgado - FVS. E-mail: anselmo@fvs.edu.br

${ }^{3} \mathrm{O}$ artigo é fruto de um trabalho de conclusão de curso em Ciências Contábeis da Faculdade Vale do Salgado (FVS).
}

Ciência e Sustentabilidade - CeS | Juazeiro do Norte v. 2, n. 1, p. 149-169, jan/jun 2016 I ISSN 2447-4606 


\section{INTRODUÇÃO}

A contabilidade é uma ciência presente em todos os vínculos sociais e em diferentes estruturas de mercado. Tal ciência auxilia o gerenciamento, embasando a tomada de decisão das pessoas físicas e jurídicas no que tange a melhor gestão do seu patrimônio. Suas ferramentas apoiam estes gestores a optarem pelas melhores alternativas que satisfaçam, simultaneamente, os produtores das informações como também os usuários da mesma. Desta forma, Ribeiro (2010, p.10) afirma que "a contabilidade é a ciência que possibilita, por meio de suas técnicas, o controle permanente do patrimônio das empresas".

Em virtude das constantes transformações que o cenário capitalista vem sofrendo desde a Revolução Industrial, a contabilidade de igual modo se transforma e se adéqua as novas mudanças. As questões socioambientais passam a ser tratadas com mais destaque nas organizações e por parte dos profissionais contábeis. Tal ênfase é oriunda de um contexto onde o número de consumidores conscientes, legislações específicas e um mercado cada vez mais competitivo emergem gradativamente. Embasados nesta conjuntura atual verifica-se que esta problemática clama por soluções rápidas para suprir não somente as necessidades dos envolvidos (stakeholders), mas também manter o equilíbrio ecológico e as questões sociais.

É nesta realidade que se constata a importância da contabilidade como mediadora e solucionadora destes assuntos. Toda esta contribuição fornecida pela contabilidade está embutida na chamada Responsabilidade Social Corporativa (RSC) dotada pelas organizações que aderem e desenvolvem posturas coerentes com as diretrizes desta nova forma de gestão.

A relação entre a contabilidade e a responsabilidade socioambiental vem evoluindo e ocupando um espaço significativo entre os profissionais contábeis. Fundamentados nas observações feitas acima foi levantada a seguinte questão: qual o nível de entendimento dos profissionais contábeis da cidade de Icó/CE com relação à responsabilidade social e ambiental?

A partir desta premissa, acompanhando a evolução do tema optado, foi escolhido como objetivo geral da pesquisa verificar a relação entre o nível de entendimento sobre o assunto abordado e o tempo de formado dos profissionais 
investigados com ênfase na relevância do assunto apresentado como também proporcionando uma óptica diferenciada da ciência contábil a partir de uma perspectiva socioambiental.

Para o embasamento do trabalho foi realizado um estudo junto aos profissionais contábeis registrados e atuantes. O estudo foi do tipo exploratório e de natureza quantitativa. Almejando o êxito da pesquisa, foi aplicado um questionário contendo 14 questões aos profissionais contábeis com escritórios na referida cidade.

\section{RESPONSABILIDADE SOCIAL CORPORATIVA - BREVE HISTÓRICO}

A Responsabilidade Social Corporativa (RSC) torna-se motivo de discussão e manifestação a partir do século XX. Corroborando com a Fundação Associação Voluntários para o Serviço Internacional (AVSI) (2011). Notoriamente, em um cenário onde a competitividade e a interdependência entre os países tornaram-se mais intensas, as políticas liberais ocuparam o espaço das políticas sociais por parte do Estado, intensificando ainda mais a negligência do setor privado para com consumidores, meio ambiente e o trabalhador. A Fundação AVSI (2011) ainda afirma que toda esta postura originou o chamado Welfare State ou Estado do BemEstar Social, concebido pelo economista britânico John Maynard Keynes, que trouxe de volta a chamada justiça social incumbindo ao Estado a criação de mecanismos para a execução da mesma. Até certo período, o Estado cumpriu com tal missão, no entanto, algumas crises econômicas provocaram o seu afastamento das questões sociais e demonstrando às empresas que estas também são responsáveis pelo cenário de injustiça social.

Desta forma, na década de 1950 nos Estados Unidos inicia-se discussões a respeito da Responsabilidade Social Corporativa (RSC) da importância de suas ações. No entanto, de acordo com a Aliança Grupo Capoava (2010) é na década de 1980 e posteriormente em 1990 no Brasil, que a questão passa a adentrar e influenciar o meio empresarial, alterando a maneira de como as empresas enxergavam a sociedade e implantando uma nova mentalidade evidenciando que a responsabilidade pelo desenvolvimento não era tão-somente um cargo do Estado. Fundação AVSI (2011) caracteriza este momento histórico como a Era da 
Responsabilidade e atribui ao setor privado à responsabilidade socioambiental, promovendo assim a sustentabilidade nos negócios.

O termo RSC ainda é considerado recente em nosso país, tendo em vista que os fatores históricos como a evolução tecnológica e a globalização fizeram com que $\circ$ Estado se preocupasse mais com assuntos que satisfizessem assuntos particulares. Portanto, pode-se constatar que a Responsabilidade Social Corporativa (RSC) ou também denominada empresarial está evoluindo gradativamente e confirmando ainda mais que esta não somente é uma reponsabilidade do Estado, mas de todos, inclusive da contabilidade.

\title{
2.1 Abordagem Conceitual - Responsabilidade Social Corporativa
}

A RSC encontra diversos conceitos para explicarem esta postura diferenciada perante as práticas empresarias, uma vez que os anseios individuais com relação aos aspectos econômicos desenvolvem gradativamente. De tal modo, o Instituto ETHOS aborda a seguinte definição:

\begin{abstract}
A forma de gestão que se define pela relação ética e transparente da empresa com todos os públicos com os quais ela se relaciona e pelo estabelecimento de metas empresariais compatíveis com 0 desenvolvimento sustentável da sociedade, preservando recursos ambientais e culturais para gerações futuras, respeitando a diversidade e a redução das desigualdades sociais (INSTITUTO ETHOS, 2013, p. 16).
\end{abstract}

Fundamentados neste conceito do Instituto ETHOS, pode-se entender que a RSC é desenvolvida pela organização que considera os interesses de todos os envolvidos (stakeholders) no processo de gerenciamento da mesma, como os acionistas, clientes, fornecedores, funcionários e demais.

Contudo, as organizações necessitam compreender que são dependentes do meio ambiente e são responsáveis por questões sociais, entendendo que ao explorarem demasiadamente tais recursos as empresas podem sofrer danos futuros e prejudicar o progresso de seus negócios. É um processo composto por mudanças estratégicas nos planos da empresa e implantação de técnicas socioambientais que promovam efeitos positivos.

Um pesquisador da área contábil assim classifica:

O conceito de responsabilidade social corporativa pressupõe que a organização não seja somente um agente econômico, produtor de riqueza e gerador de lucros, mas, também, um agente social, com participação e influência sobre o seu entorno. Tendo como objetivo não só o retorno ao acionista, mas também a geração do bem-estar, o desenvolvimento da

Ciência e Sustentabilidade - CeS | Juazeiro do Norte v. 2, n. 1, p. 149-169, jan/jun 2016 
comunidade onde atua, a sua colaboração na preservação do meio ambiente e a criação de condições de trabalho favorável (KROETZ, 2003 apud Conselho Regional de Contabilidade/RS, 2009, p.12).

Segundo Fundação AVSI (2011), a RSC pode ser subdividida em três esferas de atuação: o ambiente interno de trabalho, o meio ambiente e a sociedade. As características principais das práticas socialmente responsáveis adotadas pelas empresas é o sentimento de responsabilidade desempenhado de maneira espontânea e não simplesmente como um comprometimento de caráter jurídico.

Esta postura vai além de uma simples ação filantrópica ou obra de caridade avulsa, trata-se de um empenho da organização. De acordo com o Azevedo (2013), pode-se citar como vantagens para a empresa: a promoção da imagem, incentivos fiscais com redução de tributos, demonstra o compromisso no desempenho do país, motivação e confiança na resolução das dificuldades e garantia do bom aproveitamento dos recursos doados ou investidos. Azevedo (2013) também cita que há vantagens para os funcionários: fortalece o espírito de equipe, facilita o desenvolvimento de novas habilidades e a adequação a novas funções e estimula a lealdade e respeito ao local de trabalho. Para a sociedade: provoca melhorias na comunidade, estreita os laços entre a empresa, governo e a sociedade por meio da confiança e reduz entraves socioambientais.

\subsection{International Organization for Standardization - ISO 26000}

Serviço Brasileiro de Apoio às Micro e Pequenas Empresas (SEBRAE, 2014) assevera que a finalidade da ISO 26000 é construir uma interpretação correta do termo Responsabilidade Social, almejando conduzir todo e qualquer tipo de organização para que se tornem socialmente responsáveis fundamentadas nos princípios adotados por esta norma.

Corroborando com a Norma Brasileira NBR ISO 26000 (2010),

Responsabilidade social é a responsabilidade de uma organização pelos impactos de suas decisões e atividades na sociedade e no meio ambiente por meio de um comportamento ético e transparente que contribua para o desenvolvimento sustentável inclusive a saúde e o bem-estar da sociedade; leve em consideração as expectativas das partes interessadas; esteja em conformidade com a legislação aplicável e seja consistente com as normas internacionais de comportamento; esteja integrada em toda a organização e seja praticada em suas relações (NBR ISO 26000, 2010, p.16).

Ciência e Sustentabilidade - CeS | Juazeiro do Norte v. 2, n. 1, p. 149-169, jan/jun 2016 
Moynier et al. (2013) certifica que o cidadão moderno clama por um mundo melhor e as técnicas de RSC representam a concretização da promoção de uma coletividade economicamente viável, socialmente equitativa e ambientalmente sustentável, uma vez que as empresas podem recorrer a métricas que confirmem suas práticas responsáveis.

A ISO 26000 elencou sete princípios que servem de bússola para a Responsabilidade Social Corporativa considerando diferentes culturas organizacionais como também os distintos ramos de atividades. São eles: accountability, transparência, comportamento ético, respeito pelos interesses das partes interessadas, respeito pelo estado de direito, respeito pelas normas internacionais de comportamento e respeito pelos direitos humanos.

\title{
3 A CONTABILIDADE COMO FERRAMENTA DE MATERIALIZAÇÃO E MENSURAÇÃO DA RSC
}

Sabe-se que contabilidade é uma ciência que auxilia o gerenciamento e controle do patrimônio a fim de promover a melhor seleção de alternativas na tomada de decisão. A contabilidade é facilmente identificada como uma ciência gerencial voltada para os aspectos econômico-financeiros, mas também é detentora de uma característica social aplicada onde utiliza todas as suas técnicas e estratégias para a promoção do bem-estar social.

Assim, Jochem (2008, p. 26) comenta:

\begin{abstract}
Um Contabilista ético, responsável socialmente e bem preparado, contribui de forma direta à transformação da sociedade como um todo, tornando-se um agente multiplicador da responsabilidade social. A Contabilidade como mecanismo ativo e dinâmico dentro da sociedade, assim caracterizada na pessoa do Contabilista, alcança todas as áreas da convivência dentro da sociedade, com possibilidade de promover mudanças substanciais na vida das pessoas (JOCHEM, 2008, p.26).
\end{abstract}

Considerando a função deste profissional e refletindo nas temáticas socioambientais pode-se asseverar que a contabilidade é uma autêntica ferramenta para a execução da RSC, uma vez que suas informações expressam de maneira clara e material as práticas e os impactos provocados por cada entidade.

Filho e Milani (2010), afirmam que por meio da contabilidade a publicação de informações socioambientais passa a ocupar importante espaço nos processos econômicos. Este evento caracteriza-se pelo envolvimento dos profissionais Ciência e Sustentabilidade - CeS | Juazeiro do Norte v. 2, n. 1, p. 149-169, jan/jun 2016 
contábeis com os assuntos sociais, principalmente aqueles de responsabilidade corporativa. Desta forma, os gestores encontram através das informações contábeis fidedignas, subsídios essenciais para fundamentarem os processos decisórios do corpo organizacional.

Levando em consideração a relevância do assunto na área contábil, o Conselho Federal de Contabilidade (CFC) elaborou e aprovou a Resolução ํㅜ 1.003, de 19 de agosto de 2004 dando origem a Norma Brasileira de Contabilidade Técnica (NBC T) 15 - Informações de Natureza Social e Ambiental Tal regulamento apresenta o seguinte texto:

15.1 - CONCEITUAÇÃO E OBJETIVOS

15.1.1- Esta norma estabelece procedimentos para evidenciação de informações de natureza social e ambiental, com o objetivo de demonstrar à sociedade a participação e a responsabilidade social da entidade.

15.1.2 - Para fins desta norma, entende-se por informações de natureza social e ambiental: a) a geração e a distribuição de riqueza; b) os recursos humanos; c) a interação da entidade com o ambiente externo; d) a interação com o meio ambiente. (CFC, 2004, p. 2).

Mediante esta norma, a entidade pode nortear suas atividades para desenvolverem ações de natureza socioambiental, uma vez que os demonstrativos são ferramentas confiáveis no que tange a geração e distribuição de riqueza.

\subsection{Abordagem conceitual-auxílio da contabilidade ao Terceiro Setor e a vertente socioambiental desta ciência}

A vertente social da ciência contábil também serve de mecanismo para orientar os cidadãos na conscientização individual de suas práticas no meio ambiente e na sociedade, quer sejam individuais ou em organizações. Somente com tal postura, pode-se alcançar um equilíbrio eficaz e suficiente para os anseios de cada setor envolvido. De tal modo, Vanzo e Souza (2008) afirmam que a consciência da cidadania, tanto pessoal, quanto corporativa, é a raiz de todo ato de preservação do meio ambiente e do bem estar da sociedade. A contabilidade tem o compromisso de acarretar, dentro do seu campo de atuação, o bem estar social.

No que diz respeito ao Terceiro Setor, os profissionais contábeis auxiliam de maneira ímpar no processo de gestão de cada entidade. São elaborações de demonstrações, alocação de recursos, transparência nas ações e obtenção de 
titulações/certificações junto aos órgãos competentes. Desta forma, Coan e Megier (2010) asseveram:

\begin{abstract}
O terceiro setor tem a sustentabilidade como um dos desafios a ser vencido pelas suas organizações. Surge, então, a necessidade de uma ferramenta que promova a transparência das ações dessas organizações e lhes dê credibilidade. A contabilidade se faz importante nesse processo, pois, como essas entidades recebem recursos públicos e privados, é necessário fornecer aos seus usuários informações e relatórios contábeis que evidenciem as operações realizadas pelas organizações. A contabilidade também atua como suporte à tomada de decisão e permite que os registros feitos sejam realizados de forma clara e consistente, de modo a possibilitar o cumprimento das exigências legais (COAN; MEGIER, 2010, p.4).
\end{abstract}

Nestas entidades, a contabilidade atua como agente responsabilizado pela prestação de contas e controle do patrimônio, uma vez que este setor sobrevive de doações, subvenções, fundos econômicos, dentre outros. Assim, Sousa (2013) afirma que as entidades do Terceiro Setor necessitam de gestores eficientes para administrarem seus recursos e não somente esperam por pessoas dotadas de espírito de boa vontade, mas de profissionais adequados para desenvolver um atendimento eficaz à comunidade.

A contabilidade ambiental ou social é um tipo de contabilização que está ganhando, gradativamente, espaço dentro das organizações atuais, não somente pela maneira como mensura e controla o patrimônio das mesmas, mas também pela transparência das informações contidas nos relatórios produzidos onde externam, de maneira confiável, ao público as ações desenvolvidas em prol do meio ambiente e também do equilíbrio social. Desta forma, esta nova modalidade de gestão pode ser assim conceituada:

A contabilidade ambiental [...] tem por objetivo registrar e controlar toda e
qualquer atividade desenvolvida ou em desenvolvimento, ocorrida ou a
incorrer, não importando se em maior ou menor relevância, desde que,
mensurável em moeda, que cause ou possa vir a causar qualquer ação
destinada a amenizar e/ou extinguir tais danos, devendo ser registrada
contabilmente em contas contábeis específicas, na data de sua ocorrência,
em consonância com o disposto nos princípios fundamentais da
contabilidade (COSTA, 2012 apud ROSSI; RIOS, 2014, p.3).

A relação da contabilidade com os segmentos sociais e ambientais requer do profissional contábil uma postura inovadora perante os novos desafios, não somente como um cidadão comum que se preocupa com o meio onde sobrevive, como também o profissional dedicado e fiel na execução de seu trabalho. Por tal motivo, o contador pode ser considerado como um mediador entre a organização e a

Ciência e Sustentabilidade - CeS | Juazeiro do Norte v. 2, n. 1, p. 149-169, jan/jun 2016 
sociedade no que se refere aos assuntos socioambientais. Dessa forma, utiliza-se de ferramentas elaboradas minuciosamente onde consta toda esta situação tais como o Balanço Social (BS) e a Demonstração do Valor Adicionado (DVA).

\subsection{Demonstrações da Responsabilidade Social - Balanço Social e a DVA}

Para a comprovação material da RSC desenvolvida pelas entidades existem diferentes modelos de relatórios que podem ser elaborados em concordância com os critérios de cada organização. Desta forma, o CRC/RS (2009) profere que não há um modelo específico para preparar um Relatório Social e Ambiental, tanto no Brasil como também em níveis internacionais. Existem diversificados exemplares que atendem as proposições de cada entidade. Tais modelos são denominados como, por exemplo, Balanço Social, Relatório Social, Informe Social, Relatório de Sustentabilidade, entre outros.

Fundamentados nesta assertiva, compreende-se que uma das demonstrações adotadas pelas empresas é a elaboração e publicação do Balanço Social, ressaltando a sua originalidade e relevância das informações expressas em seu conteúdo.

O Balanço Social é uma demonstração que contém informações referentes às práticas socioambientais desenvolvidas por uma organização e que serve de prestação de contas para os stakeholders.

O balanço social é um demonstrativo publicado anualmente pela empresa
reunindo um conjunto de informações sobre os projetos, benefícios e ações
sociais dirigidas aos empregados, investidores, analistas de mercado,
acionistas e à comunidade. É também um instrumento estratégico para
avaliar e multiplicar o exercício da responsabilidade social corporativa. No
balanço social a empresa mostra o que faz por seus profissionais,
dependentes, colaboradores e comunidade, dando transparência às
atividades que buscam melhorar a qualidade de vida para todos. Ou seja,
sua função principal é tornar pública a responsabilidade social empresarial,
construindo maiores vínculos entre a empresa, a sociedade e o meio
ambiente. O balanço social é uma ferramenta que, quando construída por
múltiplos profissionais, tem a capacidade de explicitar e medir a
preocupação da empresa com as pessoas e a vida no planeta (IBASE,
2014, p.1).

Desta forma, verifica-se que o BS é um demonstrativo pleno, autêntico e hábil para a comprovação das práticas da organização nos seguintes setores: econômico social e ecológico.

Ciência e Sustentabilidade - CeS | Juazeiro do Norte v. 2, n. 1, p. 149-169, jan/jun 2016 


\subsubsection{Estrutura do Balanço Social}

Em relação ao conteúdo do Balanço Social (BS), já se sabe que o demonstrativo trata de questões econômicas, sociais e ambientais que afetam direta e indiretamente os envolvidos no processo de gestão. Quanto ao processo de elaboração do Balanço Social em uma organização, em relação à participação dos departamentos funcionais da mesma, Tinoco (2001) destaca o departamento de pessoal, o departamento de contabilidade e o departamento de sistema de informação contábil atuam diretamente em tal processo. O setor pessoal é a seção que engloba os empregados desde a sua admissão até a saída da empresa. Portanto, refere-se a planejamento, treinamento, controle, dentre outros. 0 departamento de contabilidade é o setor encarregado todos os atos e fatos administrativos de uma organização, de onde se originam os relatórios contábeis como Balanço Patrimonial, Demonstração do Resultado do Exercício e outros demonstrativos gerenciais. Já o departamento de sistema de informação contábil: é a subdivisão que reúne os dados e informações monetárias e não monetárias cuja finalidade é o embasamento na tomada de decisão de seus usuários internos e externos.

Corrêa (2009) comenta que o BS, em suas origens, abordava apenas assuntos referentes aos recursos humanos, cujo alvo era tão-somente fornecer informações aos usuários internos da empresa e ao Governo. Com o passar dos anos e consequentemente o progresso das questões econômicas e socioambientais, o BS tornou-se mais vasto abrangendo o Balanço do Pessoal, a Demonstração do Valor Adicionado (DVA), o Balanço Ambiental e a Responsabilidade Social Corporativa.

\subsubsection{Demonstração do Valor Adicionado (DVA)}

A Demonstração do Valor Adicionado (DVA) é utilizada como instrumento de comprovação das práticas socioambientais exercidas pelas organizações que se comprometeram com a RSC. De acordo com Ribeiro (2011), a DVA é um demonstrativo contábil que comprova o quanto de riqueza foi gerada pela empresa, ou seja, o valor que a mesma adicionou, e de que maneira esta parcela foi 
distribuídos entre empregados, governos, acionistas e demais envolvidos, além de externar também a quantia retida.

De acordo com Corrêa (2010), a DVA, apesar de ser preparada por intermédio de informações retiradas da Contabilidade, especialmente da Demonstração do Resultado do Exercício (DRE), evidencia o resultado da organização com maior transparência e eficácia que a DRE, pois não somente demonstra a geração do valor, mas como ele é distribuído entre os envolvidos na organização.

Nyiama (2013) assevera que:

A Demonstração do Valor Adicionado (DVA) tem por objetivo evidenciar a riqueza econômica produzida pela companhia em determinado exercício e apresentar como essa riqueza é distribuída entre os empregados, acionistas, financiadores de capital, governo, comunidade e a parcela retida na empresa para reinvestimento. Essa demonstração possibilita a avaliação do desempenho social e empresarial por intermédio da distribuição da riqueza gerada (NYIAMA, 2013, p.68).

Denota-se então que a DVA pode ser empregada como um fiel demonstrativo no que se refere à distribuição dos recursos de uma organização, pois expressa a parcela distribuída e retraída pela empresa e, portanto, passa a fazer parte do Balanço Social.

\section{METODOLOGIA}

O presente trabalho transcorreu durante o período de 30 de junho de 2014 a 10 de outubro de 2014, possuindo como público-alvo os profissionais com escritórios contábeis devidamente registrados no Conselho Regional de Contabilidade (CRC).

A primeira etapa foi dedicada ao levantamento do referencial teórico que serve de embasamento do artigo mediante seleção de artigos, livros e outros materiais para leitura. Posteriormente, na segunda etapa foi-se elaborado o instrumento utilizado para a obtenção dos dados da pesquisa, produzindo-se assim um questionário composto por 14 questões objetivas com modelo da Escala de Lickert. A terceira etapa constitui-se na aplicação do instrumento e na posterior tabulação e discussão dos dados obtidos fazendo uso do programa Microsoft Excel, versão 2010.

Ciência e Sustentabilidade - CeS | Juazeiro do Norte v. 2, n. 1, p. 149-169, jan/jun 2016 


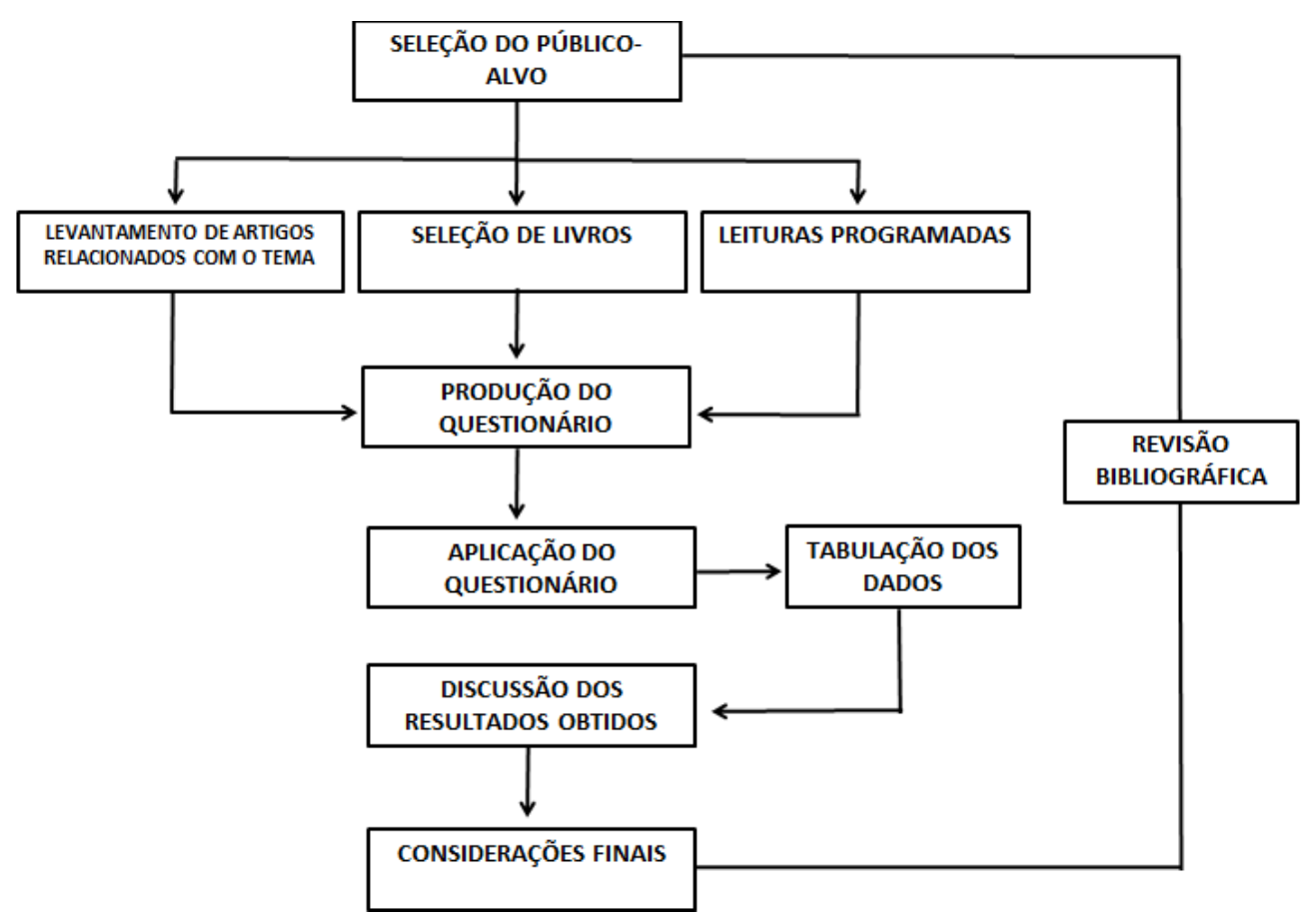

Figura 01: Fluxograma Metodológico

\section{ANÁLISE E DISCUSSÃO DOS RESULTADOS}

A seguir serão analisados os resultados obtidos dos citados profissionais. $\mathrm{Na}$ tabela 01 estão expressas as caracterizações dos investigados.

Tabela 1 - Caracterização dos contadores que participaram do estudo

\begin{tabular}{|c|c|c|}
\hline $\begin{array}{c}\text { Itens } \\
\text { considerados } \\
\end{array}$ & Parâmetros & Freq. Relativa (\%) \\
\hline \multirow{2}{*}{ Sexo } & Feminino & 61,54 \\
\hline & Masculino & 38,46 \\
\hline \multirow{4}{*}{$\begin{array}{l}\text { Tempo de atuação } \\
\text { como profissional }\end{array}$} & $<$ de 5 anos & 23,08 \\
\hline & De 5 a 10 anos & 23,08 \\
\hline & De 11 a 15 anos & - \\
\hline & $>$ de 15 anos & 53,84 \\
\hline \multirow{4}{*}{ Tempo de formado } & $<$ de 5 anos & 30,77 \\
\hline & De 5 a 10 anos & 15,38 \\
\hline & De 11 a 15 anos & 23,08 \\
\hline & $>$ de 15 anos & 30,77 \\
\hline \multirow{5}{*}{ Escolaridade } & Graduação incompleta. & - \\
\hline & Graduação compl. & 38,46 \\
\hline & Técnico & 30,77 \\
\hline & Especialização incomp. & - \\
\hline & Especialização compl. & 30,77 \\
\hline
\end{tabular}

Ciência e Sustentabilidade - CeS | Juazeiro do Norte v. 2, n. 1, p. 149-169, jan/jun 2016 


\begin{tabular}{cc}
$\begin{array}{c}\text { Mestrado incompl. } \\
\text { Mestrado compl. } \\
\text { Outro }\end{array}$ & - \\
\hline Fonte: Dados do Estudo (2014) & - \\
\hline
\end{tabular}

Levando em consideração o tempo de atuação e de formação, constatou-se que a maior parte destes profissionais já atuava na área há mais de 15 anos $(53,84 \%)$ e obtiveram sua formação posteriormente, tendo em vista a necessidade de atualização. Observa-se que tal carência pôde ser suprida mediante a implantação do Curso de Ciências Contábeis da Faculdade Vale do Salgado (FVS) na cidade de Icó/CE, pois estes profissionais totalizam um percentual de $46,15 \%$ que corresponde aos contadores formados há 10 anos. Tal pode ser comprovada mediante o somatório do número de profissionais que possuem títulos de graduação e especialização completa $(69,23 \%)$.

Tabela 2 - Distribuição dos investigados quanto ao nível de entendimento sobre a relação da atividade contábil e as questões socioambientais.

Enquete

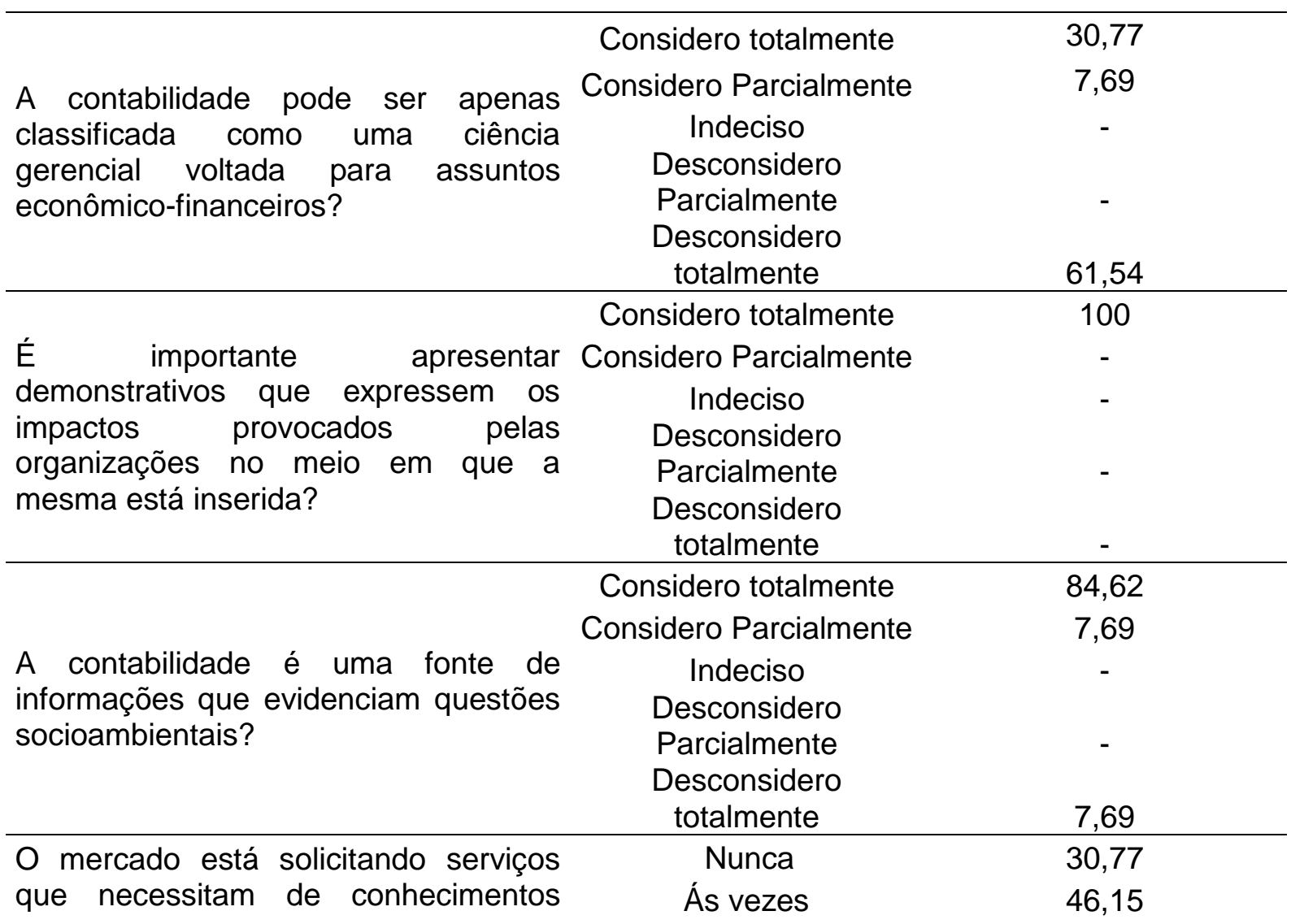


referentes à Responsabilidade Social Corporativa? Sempre 23,08

Fonte: Dados do Estudo (2014)

A tabela 02 tem o seu enfoque no nível de entendimento dos investigados quanto à relação da atividade contábil e as questões socioambientais. Mediante os dados, uma das questões aborda a respeito da contabilidade como uma ciência voltada apenas para a solução de problemas econômico-financeiros. Verificou-se que $61,54 \%$ dos entrevistados desconsideram totalmente que a Ciência Contábil possa atender somente o setor financeiro, ou seja, a contabilidade vai além tendo em vista que suas funções atendem os demais requisitos e é considerada uma ferramenta de gestão em qualquer área de atuação. Este resultado veio ao encontro do que Jochem (2008) afirmou que a contabilidade é uma estrutura ativa e dinâmica engajada na sociedade na pessoa do contabilista que exerce suas funções promovendo mudanças substanciais na vida das pessoas em diversas áreas.

Apesar de $38,46 \%$ dos investigados considerarem parcial e totalmente que a Ciência Contábil atenda atualmente somente o setor econômico, observa-se que, de maneira unânime $(100 \%)$, os profissionais concordam que é importante apresentar demonstrativos que expressem os impactos provados pelas organizações no meio em que está inserida. Tal resultado corrobora com Filho e Milani (2010) onde expressam que mediante a contabilidade e seus demonstrativos bem como a divulgação das informações socioambientais ocupam um espaço importante nestes processos econômicos.

O quesito subsequente se refere à contabilidade como fonte de informações que evidenciam questões socioambientais e foi-se observado que $84,62 \%$ dos investigados consideram totalmente que a ciência contábil pode ser utilizada para este fim, uma vez que é uma ciência presente em todas as relações econômicas e sociais da sociedade civil. Os que consideram parcialmente $(7,69 \%)$ e desconsideram totalmente $(7,69 \%)$ estão entre aqueles que afirmam que a contabilidade atenda somente a vertente econômico-financeiro (38,46\%), no entanto, exaltam a importância da publicação de demonstrativos para externarem os impactos socioambientais.

A indagação posterior aborda a respeito do mercado e da solicitação por parte do mesmo no que tange os assuntos socioambientais. Dos entrevistados $46,15 \%$ afirmaram que somente às vezes o mercado solicita tais questões, já Ciência e Sustentabilidade - CeS | Juazeiro do Norte v. 2, n. 1, p. 149-169, jan/jun 2016 
$23,08 \%$ relataram que esta prática é frequente. Portanto, este resultado demonstra assim que é um processo gradativo e presente e que a sociedade influencia diretamente na postura das empresas como também dos profissionais no que tange a realização de seu trabalho. De tal forma, Moynier et al (2013) já certificaram que as pessoas estão clamando por um ambiente melhor e as práticas da RSC são a concretização desta coletividade econômica, social e ambientalmente viável, através das práticas responsáveis das organizações.

O gráfico 01 trata dos meios utilizados para a atualização dos profissionais contábeis com relação aos assuntos socioambientais. Constatou-se que a maioria busca atualizações mediante palestras (31\%) seguidas de cursos (23\%), seminários dos CRC's (7\%) e assinaturas de revistas (8\%). A pesquisa apresentou também que ainda há um percentual que não se engaja nesta situação (31\%). Verifica-se, portanto, que já existe uma postura do profissional contábil no que tange a busca informações enaltecendo a importância do assunto, uma vez que o tema é de grande relevância na área contábil e o próprio Conselho Federal de Contabilidade (CFC) aprovou e elaborou medidas como a NBC T 15 - Informações de Natureza Social e Ambiental para regulamentar esta prática. Desta forma, evidencia-se ainda que haja uma necessidade de atualizações mais aprofundadas em tais assuntos.

\section{Gráfico 1 - Distribuição dos investigados quanto aos meios que utilizam para se atualizar com relação aos assuntos socioambientais.}

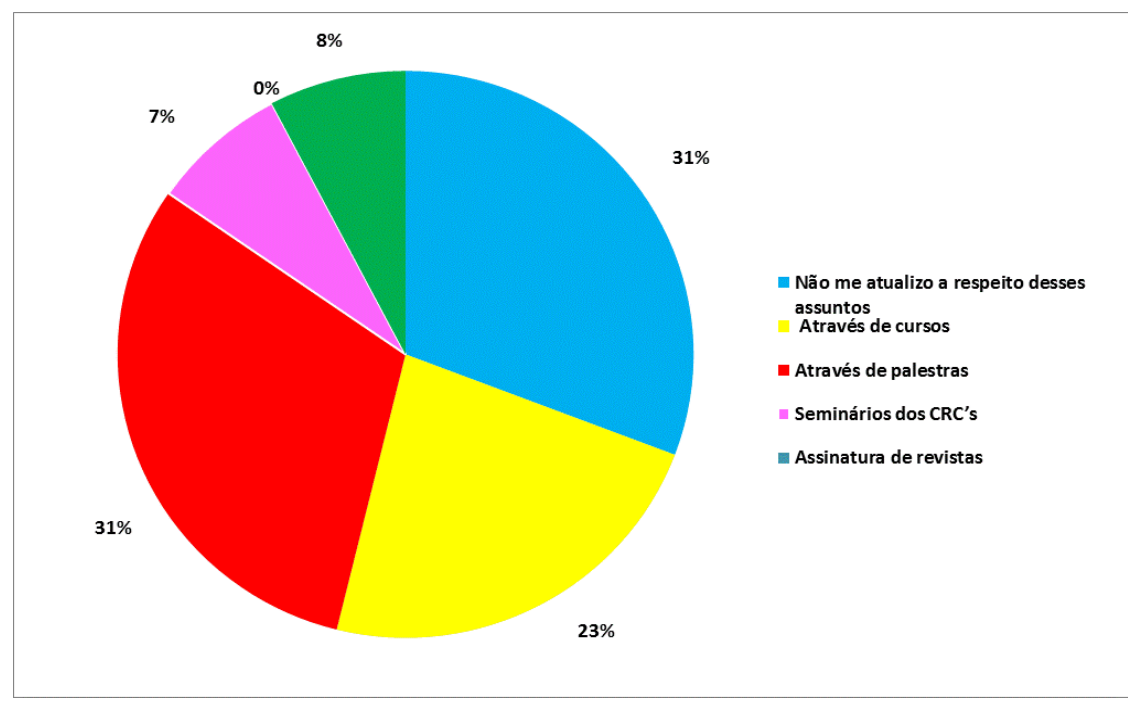

Fonte: Dados do Estudo (2014)

De acordo com a tabela 03 e com relação aos trabalhos destes profissionais, foi levantado um questionamento a fim de identificar se há ou não atividades com 
RSC desenvolvidas dentro de sua contabilidade. Dos investigados 76,92\% proferiram que ainda não há trabalhos referentes a esta questão, apesar de reconhecerem a importância do tema e afirmarem que buscam por atualizações (Figura 01). Este fato é justificado tendo em vista que a cobrança do mercado não ocorre ainda de maneira intensificada $(23,08 \%$ - Tabela 02$)$ no que tange esta problemática.

Tabela 3 - Nível de entendimento e aplicação de alguns aspectos que envolvem a gestão socioambiental nas atividades dos investigados

\begin{tabular}{|c|c|c|}
\hline Enquete & Parâmetros & $\begin{array}{c}\text { Freq. Relativa } \\
(\%)\end{array}$ \\
\hline \multirow{2}{*}{$\begin{array}{l}\text { Durante seu processo de formação } \\
\text { acadêmica, conhecimentos relacionados } \\
\text { sobre Responsabilidade Social Corporativa } \\
\text { foram abordados de que maneira? }\end{array}$} & $\begin{array}{l}\text { Superficial } \\
\text { Plena }\end{array}$ & $\begin{array}{c}53,85 \\
-\end{array}$ \\
\hline & Não foram abordados & 46,15 \\
\hline \multirow{3}{*}{$\begin{array}{l}\text { Atualmente, esse tema Responsabilidade } \\
\text { Social Corporativa é tratado dentro da sua } \\
\text { contabilidade? }\end{array}$} & Nunca & 76,92 \\
\hline & Ás vezes & 15,38 \\
\hline & Sempre & 7,70 \\
\hline \multirow{4}{*}{$\begin{array}{l}\text { Qual seu nível de conhecimento quanto ao } \\
\text { conceito, fundamentos e implicações } \\
\text { relacionado ao Balanço Social? }\end{array}$} & Nenhum & 23,08 \\
\hline & Básico & 61,54 \\
\hline & Intermediário & - \\
\hline & Avançado & 15,38 \\
\hline \multirow{4}{*}{$\begin{array}{l}\text { Você tem conhecimento da Demonstração } \\
\text { do Valor Adicionado (DVA) e de sua } \\
\text { importância? }\end{array}$} & Nenhum & 23,08 \\
\hline & Básico & 46,15 \\
\hline & Intermediário & 23,08 \\
\hline & Avançado & 7,69 \\
\hline \multirow{5}{*}{$\begin{array}{l}\text { No que se refere ao terceiro setor e suas } \\
\text { funções sociais, é importante a presença do } \\
\text { profissional contábil nesta área como agente } \\
\text { multiplicador responsabilizado pela } \\
\text { prestação de contas de tais entidades? }\end{array}$} & Considero totalmente & 100 \\
\hline & Considero Parcialmente & - \\
\hline & Indeciso & - \\
\hline & Desconsidero Parcialmente & - \\
\hline & Desconsidero totalmente & - \\
\hline
\end{tabular}

Posteriormente foi verificado o grau de entendimento sobre o Balanço Social e atestou-se que $61,54 \%$ possuem noção básica sobre o demonstrativo. Já a Demonstração do Valor Adicionado (DVA) apresentou uma porcentagem de 23,07\% de conhecimento intermediário. Conclui-se que este conhecimento superficial de tais demonstrações é consequência de que não houveram estudos da RSC trabalhados de maneira aprofundada hábeis durante o processo de formação destes profissionais. Ambas as demonstrações são utilizadas para a mensuração e materialização da RSC. O BS é abrangente e apresenta todas as ações 
desenvolvidas em prol da responsabilidade socioambiental e a DVA compõe o BS no que tange a geração da riqueza pela empresa e a distribuição dos recursos.

A questão seguinte abordou a parte referente ao terceiro setor e a presença do profissional contábil como agente multiplicador e responsável pelo melhor gerenciamento destas entidades. De maneira unânime (100\%) afirmaram convictos de que o contador é uma peça fundamental nesta área, uma vez que possui conhecimentos capazes de gerir e obter recursos para tais instituições. Tal resultado comprova o que Coan e Megier (2010) afirmaram quando relatam a respeito de a contabilidade é de vital importância no processo destas entidades, uma vez que seus usuários necessitam de informações que transpareçam as operações realizadas e a pessoa do contabilista é responsável pelo cumprimento legal de tais registros como também um profissional hábil a fornecer suporte para a tomada de decisão.

\section{CONSIDERAÇÕES FINAIS}

O presente artigo almejou identificar o nível de entendimento dos profissionais contábeis sobre a Responsabilidade Social Corporativa (RSC) como também apresentar a ciência contábil em sua vertente social e um mecanismo de materialização e mensuração dos impactos socioambientais.

O objetivo sugerido foi alcançado no que se refere ao grau de entendimento destes profissionais, comprovando-se ser uma temática que se desenvolve gradativamente dentro da profissão contábil, verificando-se ainda que já exista, mesmo que pouca, uma cobrança por parte do mercado no que se refere às questões socioambientais e em virtude disso e de outros fatores, parte dos profissionais já busca inteirar-se desta questão através palestras, cursos, revistas e seminários.

Constatou-se também que a maior parte dos profissionais considera a contabilidade uma ciência ampla que abrange não somente o setor econômicofinanceiro, mas possui uma vertente social e é capaz de utilizar suas funções para a promoção do bem-estar socioambiental, uma vez que seus demonstrativos são peças essenciais e servem de subsídio para a tomada de decisão no que tange a 
melhor gestão do patrimônio. Os investigados também consideraram essencial a presença do profissional contábil no Terceiro Setor como agente responsável pela elaboração de demonstrações e multiplicador da responsabilidade social.

$O$ presente artigo evidencia ainda que a contabilidade, na pessoa do contabilista, não se limita apenas a resolução de problemas econômico-financeiros, pois embasados na pesquisa é uma ciência vasta e que abrange aspectos referentes às práticas socioambientais. Também, embora ainda haja um número pequeno de trabalhos da RSC dentro dos escritórios, é uma prática que é tendência de mercado e está evoluindo gradativamente e elucidando que a ciência contábil é dinâmica, pois progride e se adéqua a todas as mudanças ocorridas.

É fundamental, portanto, que haja um aumento no grau de entendimento dos profissionais contábeis sobre a RSC, uma vez que estes atuam não somente como um indivíduo hábil na realização de seu trabalho, mas também como um cidadão preocupado e capaz de contribuir no bem-estar socioambiental.

$O$ presente estudo sugere que permaneça a busca mais intensificada dos profissionais que se atualizam e uma conscientização daqueles que não possui nenhum interesse por tais questões, haja vista que existem meios específicos para estas áreas e o próprio Conselho Regional de Contabilidade incentiva tais práticas e exerce a sua função social com a publicação de seus Balanços Sociais.

\title{
STUDY ABOUT THE LEVEL OF UNDERSTANDING OF ACCOUNTING PROFESSIONALS IN THE CITY OF ICÓ/CE CONCERNING THE CORPORATE SOCIAL RESPONSIBILITY (CSR)
}

\begin{abstract}
This paper craved analyze the level of understanding of accounting professionals regarding Corporate Social Responsibility (CSR) in addition to presenting the Science Accounting in its social aspect. To obtain these data, it was held up a field study of exploratory nature and quantitative accounting professionals with offices in the city of Icó/CE in the period between July and October 2014. The instrument used for the research was a questionnaire containing 14 objective questions. Among the topics addressed a theoretical foundation of the historical context of CSR, its conceptual approach and standards for implementing the same principles with a focus on International Organization for Standardization (ISO) 26000 beyond the accounting aspect was conducted. It was found that most of the investigated believes that the accounting goes beyond the economic and financial field and affirmed convinced that exalt the importance of presenting statements that express the CSR organizations. Emphasis was also given to how accounting measurement and enforcement of environmental responsibility tool highlighting the Balanço Social (BS, or Free Balance, in a free transation)
\end{abstract}

Ciência e Sustentabilidade - CeS | Juazeiro do Norte v. 2, n. 1, p. 149-169, jan/jun 2016 
and the Demonstração do Valor Adicionado (DVA). It was observed that the search for updates happen gradually, since during the process of training of professionals not had knowledge about CSR and those who had got along superficially. Therefore, it was found that professionals consider the dynamic accounting and the accountant, the professional trained to perform its social function not only as a concerned citizen, but as an effective practice in promoting social well-being.

Keywords: Corporate Social Responsibility. Free Balance. DVA. Accounting.

\section{REFERÊNCIAS}

Aliança Grupo Capoava. Responsabilidade Social Empresarial: por que o guardachuva ficou pequeno?. 2010. Disponível em:

$<$ http://www1.ethos.org.br/EthosWeb/arquivo/0-A

888Publica\%C3\%A7\%C3\%A30\%20Alian\%C3\%A7a\%20Capoava.pdf> . Acesso em: 02 jul. 2014.

AZEVEDO, I. P. Responsabilidade social empresarial: benefícios a sociedade gerando lucratividade para empresas. IX Congresso nacional de excelência em gestão. Junho, 2013. Disponível em:<http://docplayer.com.br/7611284-

Responsabilidade-social-empresarial-beneficios-para-a-sociedade-gerandolucratividade-para-empresas.html>. Acesso em: 02 jul. 2014.

BRASIL. Associação Brasileira de Normas Técnicas (ABNT) NBR ISO 26000 (2010). Disponível em:

<http://www.pessoacomdeficiencia.gov.br/app/sites/default/files/arquivos/\%5Bfield_g enerico_imagens-filefield-description\%5D_65.pdf>. Acesso em: 04 jul. 2014.

BRASIL. Conselho Federal de Contabilidade. Normas Brasileiras De Contabilidade NBC T 15 - Informações De Natureza Social E Ambiental. Resolução CFC no 1.003, de 19 de agosto de 2004. Publicada no Diário Oficial da União em 06 de setembro de 2004. BRASíLIA, DF. Disponível em:< http://nemac.ufsc.br/files/2012/12/2nbct15.pdf>. Acessado em: 06 jul. 2014.

COAN, F. M. J; MEGIER, I. H. A contabilidade no terceiro setor: instrumento de transparência social. Revista Contabilidade \& Amazônia, Mato Grosso, v.3, n. 1. 2010. Disponível em:

<http://www.contabilidadeamazonia.com.br/artigos/artigo_59artigo_3.pdf>. Acessado em: 8 jul. 2014. 
CONSELHO REGIONAL DE CONTABILIDADE DO RIO GRANDE DO SUL (CRCRS). Demonstração da Responsabilidade Social. Porto Alegre. Junho 2009.

CORRÊA, M. E. A. Balanço Social. Brasília/DF, 2009. Disponível em: <http://repositorio.uniceub.br/bitstream/123456789/2261/2/9371941.pdf>. Acesso em: 07 jul. 2014.

CORRÊA, M. de F. A evolução da demonstração do valor adicionado no Brasil. Porto Alegre, 2010. Disponível em:

$<$ http://www.lume.ufrgs.br/bitstream/handle/10183/27194/000762995.pdf?sequence= 1>. Acesso em: 19 jul. 2014.

FILHO, M. A. F. M; HABIB, C. V. S; MILANI, A. M. M. A Responsabilidade Social Corporativa e o Papel da Contabilidade sob a Ótica Discente. Revista Sociedade, Contabilidade e Gestão, Rio de Janeiro, v. 5, n. 1. 2010. Disponível em:

<http://www.atena.org.br/revista/ojs-2.2.3-06/index.php/ufrj/article/viewFile/813/806>. Acesso em: 06 jul. 2014.

FUNDAÇÃO AVSI - Associação Voluntários para o Serviço Internacional. A empresa como fator de desenvolvimento do território. Regulamentação legislativa da responsabilidade social corporativa e do terceiro setor. Conceitos e legislação. 2011. Disponível em: < http://www.avsi.org/wpcontent/uploads/2012/10/Livro-AVSI-Responsabilidade-Social-FINAL.pdf>. Acesso em: 02 jul. 2014.

IBASE. Instituto Brasileiro de Análises Sociais e Econômicas. Balanço Social. Disponível em: < http://www.balancosocial.org.br/cgi/cgilua.exe/sys/start.htm?sid=2>. Acesso em: 06 jul. 2014.

INSTITUTO ETHOS. Glossário. Brasil: Instituto Ethos, 2013. Disponível em: <http://www3.ethos.org.br/wp-content/uploads/2013/09/Gloss\%C3\%A1rioIndicadores-Ethos-V2013-09-022.pdf>. Acesso em: 02 jul. 2014.

JOCHEM, L. O contabilista e a responsabilidade social: uma abordagem crítica da evolução histórica. Curitiba, 2008. Disponível em:

<http://laudelinojochem.com.br/wp-content/uploads/2011/10/o-contabilista.pdf>. Acesso em: 05 jul. 2014.

MOYNIER, M. R; FIGUEIREDO, E; MOYNIER, R. M. L. A; ROCHA, M. H. P. Gerenciamento de projetos: a ISO 26000 como norteadora da proposta de inserir a responsabilidade social como área de conhecimento. IX Congresso Nacional de Excelência em Gestão. Junho, 2013. Disponível em; 
<http://www.excelenciaemgestao.org/Portals/2/documents/cneg9/anais/T13_0574_3 564.pdf>. Acesso em: 12 jul. 2014.

NIYAMA, J. K.; SILVA, César A. T. Contabilidade para concursos e exame de suficiência. 3.ed. São Paulo: Atlas, 2013.

RIBEIRO, M. O. Estrutura e análises de balanços fácil. 9.ed. São Paulo: Saraiva, 2011.

, M. O. Contabilidade básica fácil. 27. ed., São Paulo: Saraiva, 2010.

ROSSI, M. F; RIOS, R. P. A importância da contabilidade ambiental na evidenciação de investimentos sustentáveis. Revista Eletrônica Gestão e Negócios, São Roque, v.5, n.1. 2014. Disponível em:

<http://www.uninove.br/marketing/fac/publicacoes_pdf/administracao/v5_n1_2014/M ariana.pdf>. Acesso em: 9 jul. 2014.

SEBRAE. Serviço Brasileiro de Apoio às Micro e Pequenas Empresas. Conheça a ISO 26000. Disponível em: <http://gestaoportal.sebrae.com.br/setor/cafe/osetor/legislacao/bia-14651-conheca-o-iso-26000/BIA_14651>. Acesso em: 03 jul. 2014.

SOUSA, J. S. Gestão estratégica no terceiro setor: um estudo sobre a visão dos stakeholders. Patos, 2013. Disponível em:

<http://dspace.bc.uepb.edu.br:8080/xmlui/bitstream/handle/123456789/3861/PDF\%2 0-\%20Janice\%20dos\%20Santos\%20Sousa.pdf?sequence=1>. Acesso em: 20 ago. 2014.

TINOCO, J. E. P. Balanço social: uma abordagem da transparência e da responsabilidade pública da organização. São Paulo: Atlas, 2001.

VANZO, G. F. S; SOUZA, V.P. Um estudo sobre a influência da disciplina contabilidade social ou ambiental na formação profissional e social dos futuros contadores, de acordo com a percepção dos graduandos dos cursos de ciências contábeis. Gramado, 2008. Disponível em: < http://www.ccontabeis.com.br/18cbc/544.pdf>. Acesso em: 08 jul. 2014. 